\title{
PUBLISHING ABROAD: FAIR TRADE OR SHORT SELL FOR NON-ENGLISH-SPEAKING AUTHORS? A SPANISH STUDY
}

\author{
E. JIMÉNEZ-CONTRERAS, ${ }^{+}$L. FERREIRO-ALÁEZ
}

\begin{abstract}
Facultad de Biblioteconomía y Documentación. Campus de Cartuja, Universidad de Granada, Granada 18071 (Spain)
\end{abstract}

(Received December 6, 1995)

\begin{abstract}
We investigated the integration into the international scientific literature of articles published by researchers at the University of Granada (Spain) between 1976 and 1987, in journals published outside of Spain. The Science Citation Index was used to measure integration, and the articles were classified for comparison into eight fields (clinical medicine, experimental medicine, geology, chemistry, physics, biology, pharmaceutical science and mathematics). The minimum criterion for integration was considered fulfilled when the size of the two communities of citing authors considered (Spanish and non-Spanish) was equal, i.e., when the absolute number of citations in both communities was equal. On the basis of this criterion, articles in clinical medicine and experimental medicine were found to be integrated into the international literature. The regression lines for the number of citations per year in each field in the two communities of citing authors were parallel, indicating that integration of Spanish publications in these two fields was stationary. Of the fields found not to be integrated, the lines for pharmaceutical science citations in the two communities indicated little sign of future change in the proportion of Spanish to non-Spanish citations. Citations in the remaining five fields indicated a steady decrease in integration. We introduce the concept of the "drag effect" of national citations on citation indices in the international literature: a sharp increase in the number of Spanish articles published in non-Spanish journals may exceed the capacity of the international community to "absorb", understand and cite these new publications.
\end{abstract}

\section{Introduction}

In a process that began nearly 50 years ago, non-Anglophone scientific authors set out on a selective exodus toward the English-language literature in an attempt to join the mainstream of information exchange. ${ }^{1}$ The Spanish scientific literature was among those from which a steadily-increasing proportion of articles migrated toward English. ${ }^{2}$ Starting in 1982, exportation received a further stimulus by the authorities responsible for Spanish science policy, who encouraged publication in English. ${ }^{3}$

+ To whom correspondence should be addressed. 
The purpose of this study was to use citation analysis to judge the consequences of this exodus. We set out to determine how successfully these "displaced" articles had become integrated into the international scientific literature. The bibliographic data bases of the Institute for Scientific Information were consulted to obtain citation data. In this article, we define integration solely in terms of citation frequency. Our findings and conclusions thus refer strictly to relative numbers of citations. A high or low degree of integration as defined here should not be interpreted as a reflection of the degree to which concepts, methods and objectives developed by Spanish researchers have come to form part of the international body of scientific knowledge; this is something that cannot be measured with bibliometric methods.

\section{Materials and methods}

The Spanish literature was represented by all articles published in non-Spanish journals by authors from the University of Granada (Spain) and included in the Institute for Scientific Information's (ISI) Science Citation Index (SCI) for the years 1976 to 1987 , both inclusive. These articles represented approximately $4.5 \%$ of all articles from Spanish universities included in the SCI during this period. In terms of numbers of articles, the University of Granada oscillated between 4th and 5th place in the ranking of all Spanish universities during this period. ${ }^{4}$ In an earlier study, we found that $94.0 \%$ of these articles were published in English, ${ }^{5} 4.9 \%$ in French, and $1.1 \%$ in German.

A total of 6464 citations to 1619 articles in the SCI were classified into one of eight fields (observation units): clinical medicine, experimental medicine, geology, chemistry, physics, biology, pharmaceutical science and mathematics. Citations were further classified as Spanish (Spanish surname of the citing authors) or non-Spanish (all other citing authors regardless of nationality). A survey done prior to data collection showed that fewer that 3\% of non-Spanish authors had a Spanish surname. Questionable surnames were checked in other data bases of the ISI (CBD, WIPIS and CCAD) and assigned to the appropriate group. Non-Spanish authors working temporarily in Spanish university laboratories were classified as Spanish authors during their stay. (For statistical purposes, these visiting authors represented a negligible proportion of Spanish authors.)

All data were obtained by manual searches of the printed editions of annual SCI reports and entered in a database (DBASE v. IV). The data were grouped according to the field of science, and tabulated according to the year of citation and nationality of the citing authors. 
The number of publications in each of the eight fields were counted for two equal consecutive periods: 1976-1981 (Art 1) and 1982-1987 (Art 2) (Table 1). Citations from 1976 to 1987 in journals published outside Spain were classified according to scientific field. Within each field, citations were classified according to the citing authors' nationality as Spanish (cit SP) or non-Spanish (cit INT) (Table 2).

Table 1

Number of articles by researchers affiliated with the University of Granada (Spain) published in eight fields of science between 1976 and 1981 (Art 1), and between 1982 and 1987 (Art 2), inclusive

\begin{tabular}{lcc}
\hline Fields & Art 1 (76-81) & Art 2 (82-87) \\
\hline Clinical Medicine & 97 & 90 \\
Experimental Med. & 83 & 127 \\
Geology & 20 & 42 \\
Chemistry & 86 & 313 \\
Physics & 49 & 139 \\
Biology & 76 & 170 \\
Pharmaceutical Sci. & 54 & 213 \\
Mathematics & 9 & 61 \\
\hline
\end{tabular}

Source: Science Citation Index, Institute for Scientific Information, Philadelphia, PA, USA.

Table 2

Citations by Spanish (cit SP) and non-Spanish authors (cit INT) to articles published by University of Granada authors between 1976 and 1987

\begin{tabular}{lrrrr}
\hline & \multicolumn{2}{c}{$(1976-81)$} & & (1982-87) \\
\cline { 2 - 5 } & cit SP & cit INT & cit SP & cit INT \\
\hline Clinical Medicine & 46 & 222 & 83 & 427 \\
Experimental Med. & 141 & 398 & 177 & 410 \\
Geology & 25 & 35 & 151 & 105 \\
Chemistry & 134 & 233 & 1100 & 505 \\
Physics & 65 & 135 & 270 & 203 \\
Biology & 89 & 50 & 408 & 193 \\
Pharmaceutical Sci. & 5 & 4 & 83 & 35 \\
Mathematics & 60 & 40 & 40 & 225 \\
\hline
\end{tabular}

Source: Science Citation Index, Institute for Scientific Information, Philadelphia, PA, USA. 
To calculate the regression lines as a reflection of the changes in citation patterns during the period of study, we used series of cumulative citations for the years 1976 to 1987. The first number in each series was the sum of all citations in the SCI to articles by University of Granada authors during 1976 to 1982 . From 1983 until 1987, each number of the series was the sum of citations during the year in question plus citations during the previous years. These series of figures were fitted to an exponential model, and the slopes (b SP and b INT) and intercepts (a SP and a INT) of the lines for Spanish and non-Spanish citations were calculated.

The Spanish literature in a given scientific field was considered to be integrated in the international literature if the ratio of Spanish to non-Spanish citing authors (cit SP:cit INT) was equal to or great than one. If this ratio was less than one, the Spanish literature was considered not to be integrated into the international literature. With this method, the ratio cit SP:cit INT is influenced by the value of the intercepts a SP and a INT, and of the slopes b SP and b INT.

Table 3

Ratio of articles published in different fields by University of Granada authors from 1976-1981 (Art 1) to articles published from 1982-1987 (Art 2)

\begin{tabular}{lc}
\hline \multicolumn{1}{c}{ Fields } & Art $1:$ Art 2 \\
\hline Clinical Medicine & $1: 1$ \\
Experimental med. & $1: 1.5$ \\
& $1: 2.1$ \\
Geology & $1: 3.6$ \\
Chemistry & $1: 2.8$ \\
Physics & $1: 2.2$ \\
Biology & $1: 6.8$ \\
Pharmaceutical Sci. & $1: 3.9$ \\
\hline Mathematics & \\
\hline
\end{tabular}

Source: Science Citation Index, Institute for Scientific Information, Philadelphia, PA, USA.

\section{Articles published in non-Spanish joumals}

During the period studied, the articles by University of Granada authors in the fields of clinical or experimental medicine and included in the SCI increased slightly or remained stable. The number of articles in geology and biology doubled, and the 
number of articles in other fields showed even greater increases, which were especially large in mathematics and pharmaceutical science (Table 3).

\section{Citations to Spanish articles}

The cit SP: cit INT ratio for both 1976-1981 and 1982-1987 showed that publications in clinical and experimental medicine were integrated into the international literature (Table 4). The relative increase in the number of articles was smaller during the second period.

Table 4

Ratio of citations by Spanish authors to citations by non-Spanish authors between 1976 and 1981 (Art 1), and between 1982 and 1987 (Art 2), inclusive

\begin{tabular}{lcc}
\hline \multirow{2}{*}{ Fields } & \multicolumn{2}{c}{ cit SP : cit INT } \\
\cline { 2 - 3 } & $1976-81$ & $1982-87$ \\
\hline Clinical Medicine & $1: 4.8$ & $1: 5.1$ \\
Experimental Med. & $1: 2.8$ & $1: 2.3$ \\
Geology & $1: 1.4$ & $1: 0.7$ \\
Chemistry & $1: 1.7$ & $1: 0.4$ \\
Physics & $1: 2.7$ & $1: 0.7$ \\
Biology & $1: 0.6$ & $1: 0.5$ \\
Pharmaceutical Sci. & $1: 0.8$ & $1: 0.4$ \\
Mathematics & $1: 0.7$ & $1: 0.6$ \\
\hline
\end{tabular}

Source: Science Citation Index, Institute for Scientific Information, Philadelphia, PA, USA.

Articles in geology, chemistry and physics were integrated during the first period, but not during the second period. The loss of integration during the second period coincided with a gradual increase in the number of articles published (Table 3 ).

Articles in biology, pharmaceutical science and mathematics were not integrated into the international literature in either of the two periods. Integration was lower during 1982 to 1987 , when the number of articles published increased two-fold to seven-fold in comparison with the first period (Table 3). 


\section{Changes in Spanish versus non-Spanish citation patterns}

The most striking finding was that, with the exception of pharmaceutical science, the growth rate of cumulative annual citations by Spanish authors (b SP) was greater than the increase in cumulative annual citations by non-Spanish authors (b INT) during the 1982-1987 period (Table 5). However, in clinical and experimental medicine (which were considered to be integrated), the theoretical numbers of non-Spanish citations (a INT) was greater than the number of Spanish citations (a SP). The similarity in the slopes for the two citing populations ( $b \mathrm{SP}=0.015, \mathrm{~b}$ INT $=0.012$ ) suggests that the integration status of publications in these two fields has not changed; this is reflected by the closely parallel lines for cumulative citations by Spanish and non-Spanish authors. In other words, citations by both populations remained stable from 1982 to 1987, with a predominance of international citations (Figs 1a and 1b).

Table 5

Correlation coefficients ( $r$ ) and values of the b-axis intercept (a) and slope (b) for the regression plots of the number of cumulated annual citations by Spanish (cit SP) and non-Spanish authors (cit INT)

\begin{tabular}{lcccrr}
\hline & r SP & r INT & b SP & b INT & a SP a INT \\
\hline Clinical Medicine & 0.989 & 0.994 & $1.131>1.116$ & $153<422$ \\
Experimental Med. & 0.998 & 0.995 & $1.184>1.172$ & $47<259$ \\
& & & & & \\
Geology & 0.994 & 0.996 & $1.439>1.185$ & $152<276$ \\
Chemistry & 0.989 & 0.992 & $1.358>1.250$ & $28<35$ \\
Physics & 0.995 & 0.997 & $1.287>1.155$ & $78<143$ \\
Biology & 0.998 & 0.983 & $1.321>1.286$ & $95>59$ \\
Mathematics & 0.979 & 0.948 & $1.544>1.352$ & $8>7$ \\
Pharmaceutical Sci. & 0.999 & 0.995 & $1.400<1.415$ & $61>35$ \\
\hline
\end{tabular}

Source: Science Citation Index, Institute for Scientific Information, Philadelphia, PA, USA.

In the fields of chemistry, geology and physics - which were integrated during the first but not the second period of study - the theoretical number of non-Spanish citations (a INT) during the first six years was greater than the number of Spanish citations (a SP). In contrast with medical articles, however, the annual growth rate of cumulative Spanish citations was much faster than the increase in international citations (Table 5). The gradual loss of integration was reflected by the convergence, and subsequent intersection, of the lines for the two citing populations. This process continued, and was especially notable in chemistry and geology (Figs $2 a, 2 b$ and $2 c$ ). 


\section{Experimental Medicine}

National vs Foreigner citing

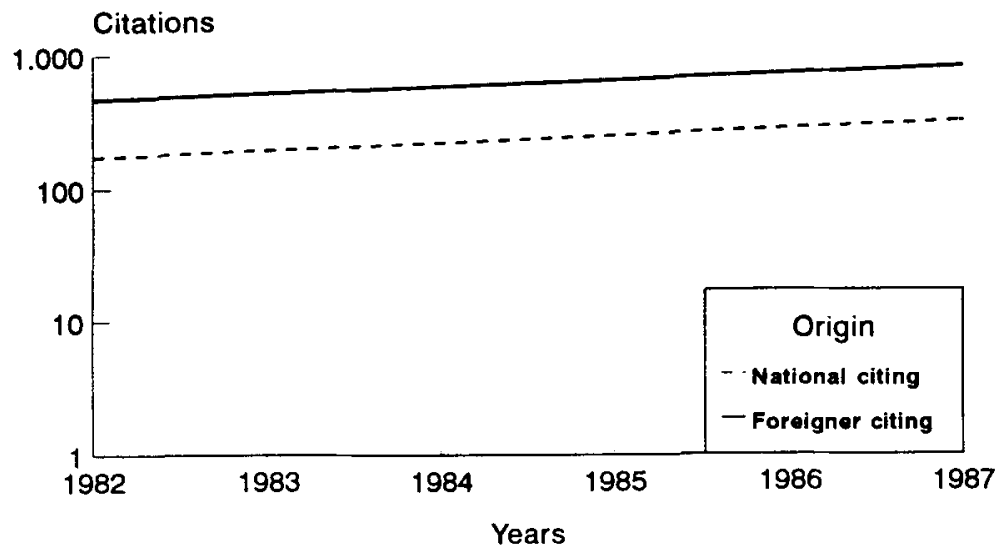

Source: SCI 1976-87

\section{Clinical Medicine}

National vs Foreigner citing

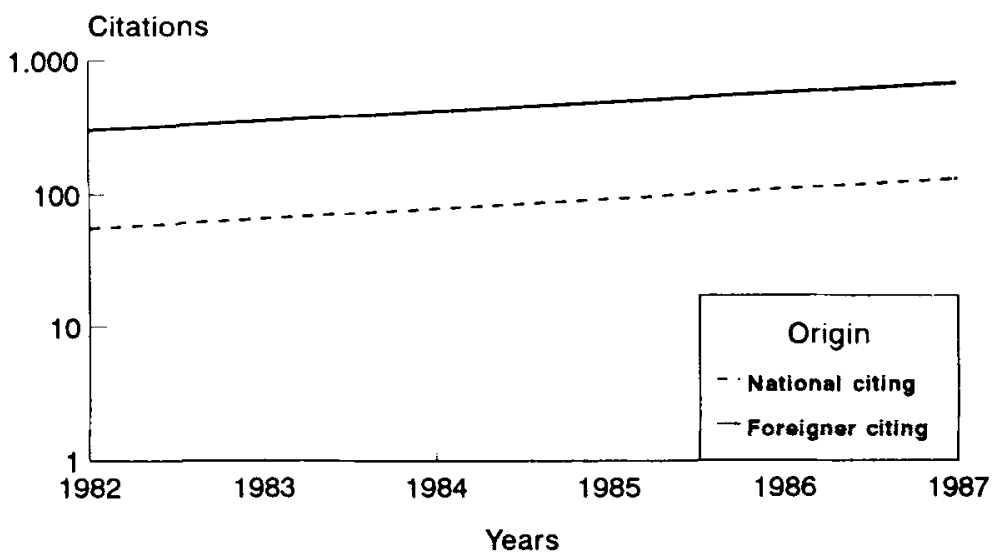

Source: $\mathrm{SCl} 1976-87$

Figs. $1 \mathrm{a}$ and $1 \mathrm{~b}$. Evolution of cumulative citations to articles published by University of Granada authors in experimental (Fig. 1a) and clinical medicine (Fig. 1b) during the period from 1982 to 1987 inclusive. Most citations were from non-Spanish authors, hence contributions to these fields by University of Granada authors were fully integrated into the international literature during this period 


\section{Chemistry}

National vs Foreigner citing

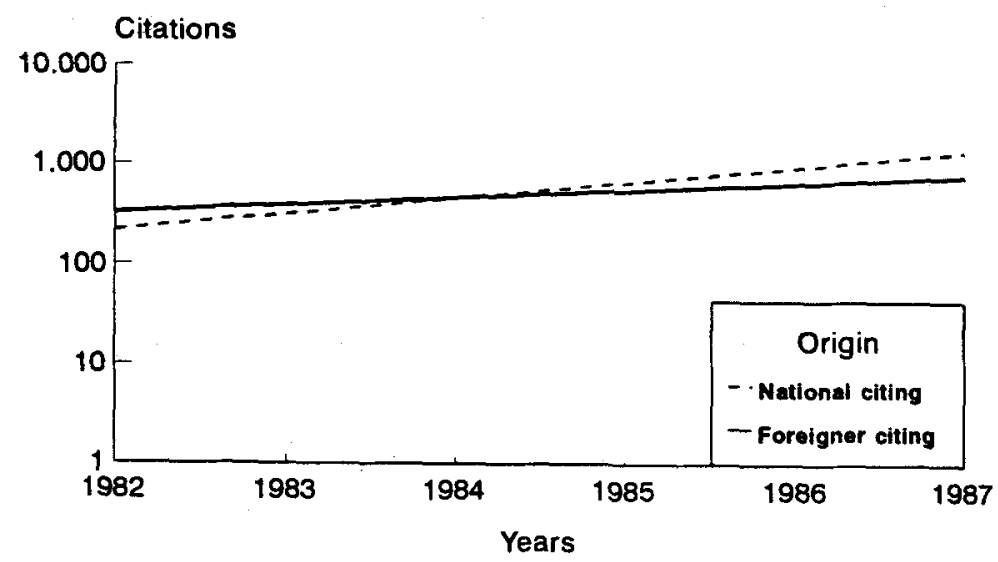

Source: SCI 1976-87

\section{Geology}

National vs Foreigner citing

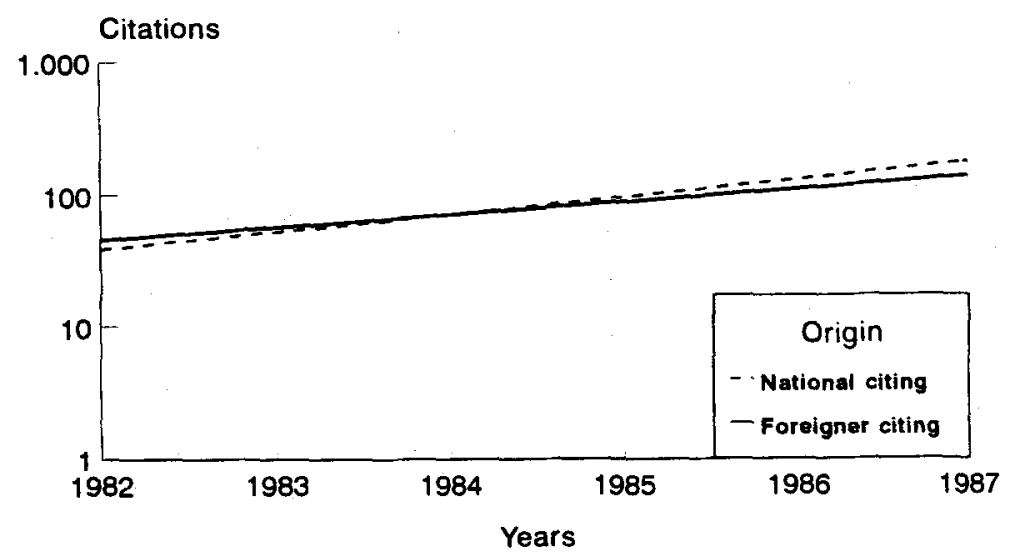

Source: SCl 1976-87 


\section{Physics}

National vs Foreigner citing

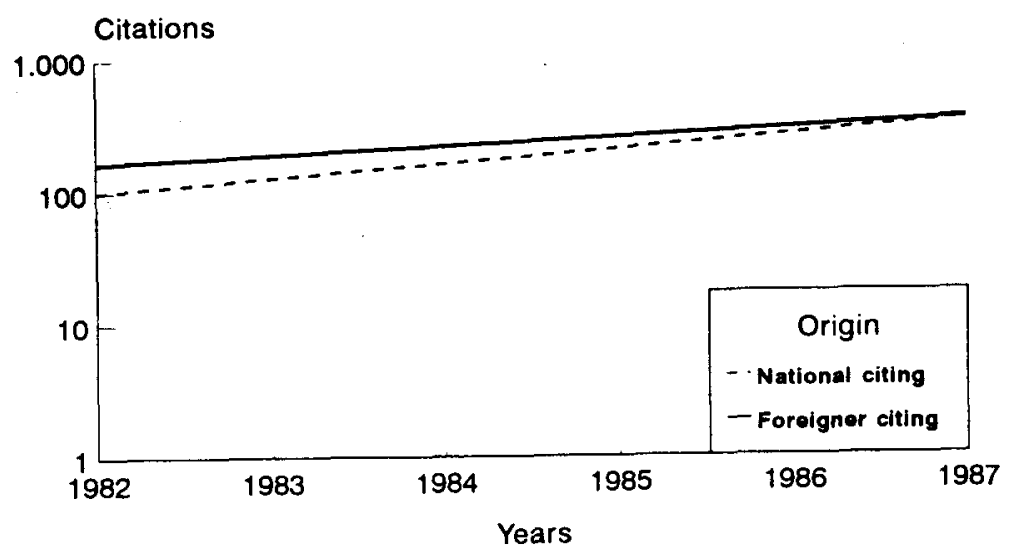

Source: SCl 1976-87

Figs. 2a, 2b and 2c. Evolution of cumulative citations to articles published by University of Granada authors in chemistry (Fig. 2a), geology (Fig. 2b) and physics (Fig. 2c) during the period from 1982 to 1987 inclusive. The rapid increase in the number of Spanish citations prevented these fields from becoming integrated into the international literature

Publications in biology and mathematics failed to satisfy our criterion for integration at any time during the 12-year study period (Table 4). In fact, the situation in these fields has worsened steadily during 1982 to 1987 (Figs 3a and 3b).

In pharmaceutical science, the lines for Spanish and non-Spanish citations remained nearly parallel throughout the study period, with a marginal difference of 0.015 in their slopes. The proportion of non-Spanish citations increased very slowly during the study period. However, in contrast to publications in medicine (Table 4), the theoretical number of initial Spanish citations (a SP) was much greater than the number of non-Spanish citations (a INT), and national citations continued to predominate throughout the study period (Fig. 4). 


\section{Biology}

National vs Foreigner citing

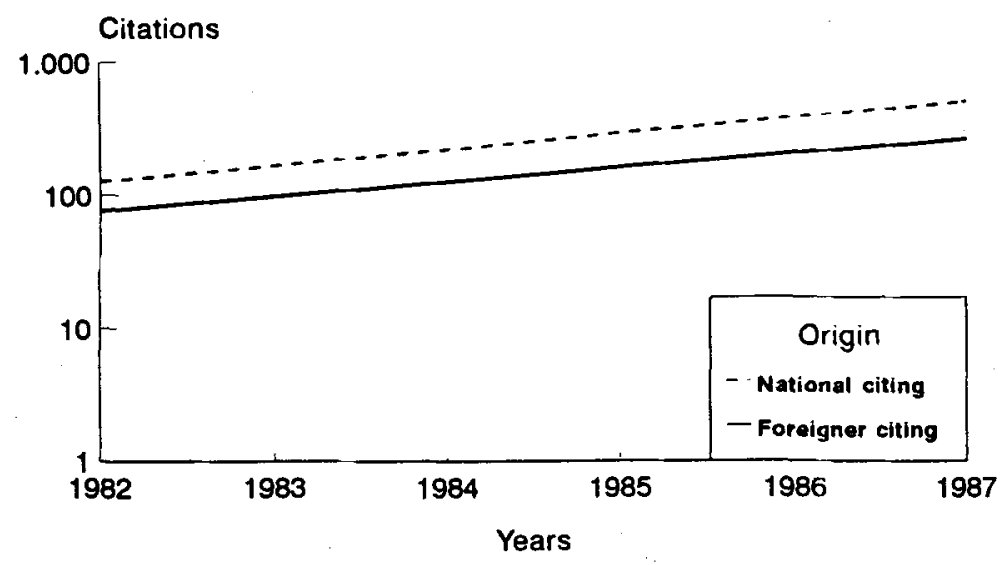

Source: SCI 1976-87

\section{Mathematics}

National vs Foreigner citing

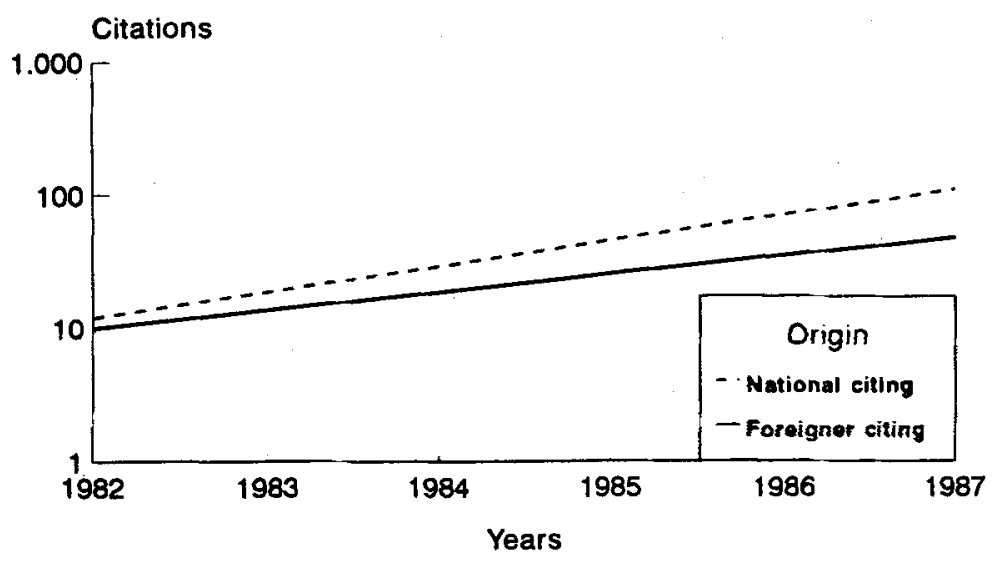

Source: SCI 1976-87

Figs. $3 \mathrm{a}$ and $3 \mathrm{~b}$. Evolution of cumulative citations to articles published by University of Granada authors in biology (Fig. 3a) and mathematics (Fig. 3b) during the period from 1982 to 1987 inclusive. These fields were not integrated into the international literature, and tended to become more marginalized with time 


\section{Pharmaceutical Science}

National vs Foreigner citing

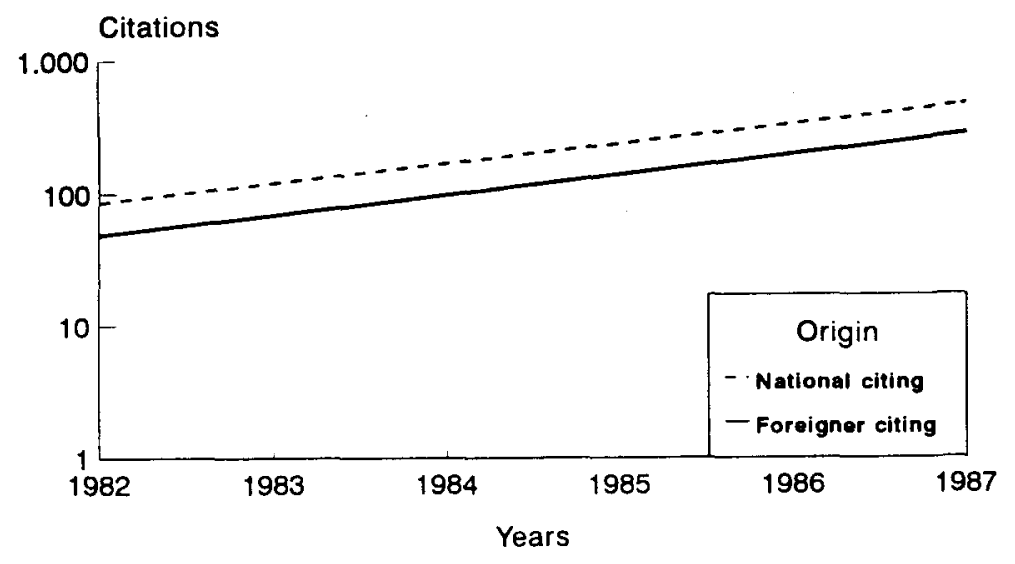

Source: $\mathrm{SCl} 1976-87$

Fig. 4. Evolution of cumulative citations to articles published by University of Granada authors in pharmaceutical science during the period from 1982 to 1987 inclusive. Although the proportion of non-Spanish citations increased during this period, this field did not become integrated into the international literature

\section{Discussion}

According to the method of evaluation proposed here, research publications from a given country can be considered integrated into the international scientific literature when the ratio of national to international citations is equal to one or higher. Implicit in our definition of equality between the two communities is the assumption that each citation represents an individual author. We did not take into account the possibility (indeed, the likelihood) that one or more national (perhaps more frequently) or international authors cited the literature under study more than once in a given year. Consequently, as the number of citations by international authors to national authors increases, this would in theory imply an increase in the community of international citing authors. This would result in the consolidation of Spanish publications within the international scientific literature in a given field. If this process continued 
indefinitely, the size of the international community of citing authors would approach a theoretical maximum, limited by the size of the SCI data base. ${ }^{6}$

For Spanish publications in clinical and experimental medicine, the international community of citing authors was larger than the national community during the entire 12-year study period. We believe the international integration of scientific output in these fields occurred because the cumulative number of citable Spanish articles remained stable (clinical medicine) or increased only slightly (experimental medicine) each year. The increase in publications in experimental medicine was too small to disturb the balance between national and international citations. In other words, the international dissemination of Spanish scientific output remained stable throughout the study period. In experimental medicine, the international community was able to adsorb the gradual increase in the number of Spanish articles published during 1982-1987.

In the other six fields of science, the total numbers of citable articles increased slightly from 1976 to 1981 , and thereafter increased from two-fold to seven-fold depending on the area. This sudden change in the balance between national to international citations led to the loss of integration in physics, chemistry and geology between 1982 and 1987. Although citations to publications by these three international communities of authors increased, the larger relative increase in citations by Spanish authors offset any gain in integration.

We believe there are two reasons for the imbalance. The unprecedented increase in the presence of articles by Spanish authors in the international literature may have exerted a "drag effect" on national citations. In fact, it seems that potential citations by Spanish authors to Spanish articles have emigrated toward non-Spanish target articles, just as articles by Spanish authors have emigrated from the national to the international literature. At the same time, the number of potential citing authors in the international community did not increase fast enough to maintain the previous (1976-1981) rates of citation to an ever-larger pool of citable articles.

The "drag effect" may also account for the decline in the integration of pharmaceutical, mathematical and biological articles during 1982 to 1987, when the predominance of Spanish citations with respect to international citations increased. This trend was documented in our analysis, although it was less obvious than the transition from integrated to a nonintegrated status in physics, chemistry and geology.

The increase in the total number of publications by Spanish authors (Art 2, Table 1) in non-Spanish journals covered in the SCI may partly account for part of the poor integration of Spanish contributions in six of the eight fields of science analyzed here. This increase in absolute numbers of citable articles has been suggested to be an 
indicator of the increasing capacity of scientific output in Spain, and implicitly, as a reflection of the appropriateness and effectiveness of measures adopted to increase the presence of Spanish research in the international literature. ${ }^{7}$ However, aside from the advantages of recent policies regarding research output and dissemination, our findings show a paradoxical, progressive shift toward a preponderance of national citations in most fields of science during the period studied.

Several studies have examined the increase in total ${ }^{8,9}$ and field-specific publications by Spanish authors ${ }^{10,11}$ in the SCI and other data bases. One circumstance that may have fomented this increase is the rise in the number of English-language source documents covered, and the comparative neglect of source documents from countries where languages other than English are used. This exclusion may have contributed indirectly to the increased presence of Spanish articles appearing in English-language journals covered in data bases. ${ }^{12}$

On the basis of the data we present here (which do not include individual publishing behavior for each author), we cannot infer that the increase in articles by University of Granada authors published in English-language journals covered in the SCI caused the decrease in articles published in Spanish journals in the SCI. Nevertheless, the sharp increase during 1982-1987 in non-medical publications by authors from our institution suggests that such an interdependence does exist. The change in authors' publication habits it a more likely explanation of the shift during the 1980 's from publishing predominantly in Spanish journals to publishing mostly in international journals. An alternative hypothesis is that from 1982 onward, a new generation of researchers systematically published their work exclusively in international journals. However, the speed of the change to English-language journals speaks against this possibility.

This shift may explain why some highly specialized Spanish journals are now finding it difficult to obtain publishable articles. Their usual pool of potential authors, comprising a relatively small community, may have decided to emigrate to Englishlanguage journals. ${ }^{13}$ The rapid change in publication habits may also go some way toward explaining why the citation rates of articles by Spanish authors are lower than those for articles by authors from most other European countries. ${ }^{14,15}$

\section{Conclusions}

1. The SCI data base recorded more than twice as many articles by Spanish authors affiliated with the University of Granada during 1982 to 1987 than during the previous 6-year period. The increase in citable articles was reflected as an increase in the 
number of citations. However, the increase in the number of citations by Spanish authors was proportionately greater than the increase in citations by non-Spanish authors. As a result, fields of Spanish science that had not become integrated (ratio of national to international citations equal to or greater than 1) into the international literature before 1982 failed to achieve integration during the following 6 years, and some fields that had previously been integrated became marginalized.

2 . The fields of experimental medicine and clinical medicine $(24.8 \%$ of all articles considered) were fully integrated into the international literature during the study period. Pharmaceutical science, biology and mathematics were not integrated, and physics, geology and chemistry, which were integrated at the start of the study, became marginalized during 1982 to 1987 . In these three fields, most citations were by Spanish authors.

3. The increase in Spanish citations to articles by University of Granada authors published in non-Spanish journals paralleled the increase in the numbers of these articles appearing in the SCI for the period from 1982 to 1987 ("drag effect"). The failure of citations by the international scientific community to increase suggests that efforts by University of Granada researchers to export their articles (and, together with this emigration, the reduction in the numbers of articles published in Spanish) has not been rewarded by an increase in the diffusion of this research in the international community.

4. Our results should not be extrapolated to other fields of research in Spain. However, our method can be used with the SCI to assess the integration of research output from other universities. The ratio of national to international citations gives a more accurate vision of the influence of a given sample of publications on international citation patterns than is provided by habitual indicators of research output used in Spain. Repetition of this study in other setting will determine the extent and patterns of emigration of articles from countries in which English is not the main language.

This study was supported in part by University of Granada research funds. We thank Karen Shashok for translating the original manuscript into English.

\section{References}

1. Cincuenta años de investigación en Física y Química. Consejo Superior de Investigaciones Científicas. Madrid, 1981.

2. E. G. Kovach, Country Trends in Scientific Productivity. ISI's Who's who in Publishing in Science. An International Directory of Scientist and Scholars in the Life, Physical and Applied Sciences, ISI, Philadelphia, USA, 1973. 
3. J. M. Rojo, El Estado y la actividad científica. In: J. M. LoPeZ Piñero (Ed.), España-Ciencia, Espana-Calpe, Madrid, 1991, pp. 113-143.

4. B. Maltras, M. A. Quintanilla, Spanish Scientific Production 1981-89. EPOC Report. University of Salamanca, CSIC, Madrid, 1992.

5. E. JIMÉNEZ-CONTRERAS, International Diffusion of Recent Scientific Literature from Granada (1975-1987), University of Granada, Departamento de Biblioteconomía y Documentación, Dissertation, Granada (Spain), 1993.

6. For more information on SCI's limitations: L. Ferreiro-Alaez, S. Ugena, Citation mechanics in journals covered by the Journal Citation Reports, Scientometrics, 24 (1992) 149-162.

7. E. Garfield, Science in Spain 1981-1992: A Citation Perspective. Speech presented at "Estudieos sobre la Ciencia y la Política Científic. Univ. International Menéndez y Pelayo. Sevilla, Spain, 20 October, 1992. (Translation into spanish in Arbor. Revista de las Artes y Ciencias, CXLVII (1994), 111-133 and 577-578.

8. P. Pascual, La evolución de las publicaciones científicas, Politica Científica, 20 (1989) 28-31.

9. J. M. RoJo, La I+D en el Mercado Unico, Política Científica, 32 (1992) 2-6.

10. I. Gómez, A. Mendez, C. Pedros, S. Barrigon, Producción bibliográfica de la farmacología experimental en España: un estudio actualizado, Revista de Farmacología Clínica y Experimental, 6 (1989) 376-386.

11. M. Bordons, F. García-Jover, S. Barrigon, Bibliometric analysis of publications of Spanish pharmacologist in the SCI (1984-1989) Scientometrics, 24 (1992) 163-177.

12. E. JimÉnEZ-CONTRERAS, Las revistas científicas: el centro y la periferia, Revista Española de Documentación Científica, 15 (1992) 174-182.

13. J. M. RINCON, Evaluación de la actividad investigadora y revistas científicas nacionales. Editorial. Boletín de la Sociedad Española de Cerámica y Vidrio, 30 (1991) 3.

14. T. Braun, W. Glänzel, A. Schubert, Scientometrics Indicators. A 32-coutnry Comparative Evaluation of Publishing Performance and Citation Impact, Workd Scientific, Singapore, 1985.

15. T. BRAUN, W. GläZEL, A topographical approach to world publications output and performance in the sciences, 1981-1985. Scientometrics, 19 (1990) 159-165. 